\title{
BMJ Open Does the architectural layout of a NICU affect alarm pressure? A comparative clinical audit of a single-family room and an open bay area NICU using a retrospective study design
}

\author{
Rohan Joshi, ${ }^{1,2}$ Henrica van Straaten, ${ }^{3}$ Heidi van de Mortel, ${ }^{4}$ Xi Long, ${ }^{5,6}$ \\ Peter Andriessen, ${ }^{4}$ Carola van $\mathrm{Pul}^{2,7}$
}

To cite: Joshi R, Straaten $\mathrm{H}$, Mortel Hv, et al. Does the architectural layout of a NICU affect alarm pressure? A comparative clinical audit of a single-family room and an open bay area NICU using a retrospective study design. BMJ Open 2018;8:e022813. doi:10.1136/ bmjopen-2018-022813

- Prepublication history and additional material for this paper are available online. To view these files, please visit the journal online (http://dx.doi org/10.1136/bmjopen-2018022813).

Received 9 March 2018 Revised 22 May 2018 Accepted 24 May 2018
A Check for updates

(C) Author(s) (or their employer(s)) 2018. Re-use permitted under CC BY-NC. No commercial re-use. See rights and permissions. Published by BMJ.

For numbered affiliations see end of article.

Correspondence to Rohan Joshi; r.joshi@tue.nl

\section{ABSTRACT}

Objectives To determine differences in alarm pressure between two otherwise comparable neonatal intensive care units (NICUs) differing in architectural layout—one of a single-family room (SFR) design and the other of an open bay area (OBA) design.

Design Retrospective audit of more than 2000 patient days from each NICU cataloguing the differences in the number and duration of alarms for critical and alerting alarms, as well as the interaction of clinicians with the patient monitor.

Setting Two level 3 NICUs.

Results A total of more than 150000 critical and 1.2 million alerting alarms were acquired from the two NICUs. The number of audible alarms and the associated noise pollution varied considerably with the OBA NICU generating $44 \%$ more alarms per infant per day even though the SFR NICU generated 2.5 as many critical desaturation alarms per infant per day.

Conclusion Differences in the architectural layout of NICUs and the consequent differences in delays, thresholds and distribution systems for alarms are associated with differences in alarm pressure.

\section{INTRODUCTION}

The architectural layout and design of a hospital department must address the potentially conflicting needs and aspirations of different stakeholders. In a neonatal intensive care unit (NICU) environment, the usual stakeholders include infants, their families, staff and the hospital administration. Infants require a developmentally supportive environment, one that minimises stressors and facilitates positive stimuli. Families desire privacy and an environment conducive to their active participation in daily caregiving while staff needs are focused on providing adequate care, regulating stress and maintaining a positive work environment.
Strengths and limitations of this study

- There are no studies investigating the relationship between neonatal intensive care unit (NICU) design and associated alarm pressure.

- This comparative clinical audit of patient monitor alarms from a single-family room and open bay area NICU generates benchmarks and may identify opportunities for improving alarm management.

- Since the study is explorative and of an observational study, the non-randomised nature is a limitation.

Over the past two decades, there has been a trend towards the adoption of the single-family room (SFR) NICU, as opposed to the traditional 'open bay-area' (OBA) design. ${ }^{12}$ Recent evidence has shown an association between the SFR design and improved neurobehavioural and medical outcomes. ${ }^{3-5}$ Also, the SFR design offers an opportunity to provide better control over stressors such as light and noise, improve parental and staff satisfaction with care, improve the work environment for nurses and possibly reduce the cost of care without increasing adverse outcomes. ${ }^{5-14}$

Nevertheless, the SFR environment with its reduced patient visibility and increased dependency on patient monitoring creates a challenge for maintaining a safe environment for infants. While former work has shown that safe patient monitoring is feasible in SFR NICUs, differences in the number of alarms generated per patient per unit time (alarm pressure) for NICUs of the SFR and the traditional OBA design remain unexplored. ${ }^{15}$ These differences are important to determine because adapting the NICU to the SFR environment can have adverse implications for alarm fatigue-a top patient safety 
concern arising due to excessive exposure of clinicians to alarms leading to sensory overload and consequently a delayed or no response to alarms. ${ }^{16-18}$ Investigations into how NICU design and associated alarm settings affect alarm pressure can thus lead to opportunities for further improving the NICU environment. While on the one hand, infants in the SFR NICUs may have reduced exposure to noise which enhances physiological stability and reduces alarms; on the other hand, long nurse response times to alarms may, in fact, result in an increased number of alarms ${ }^{1920}$ Furthermore, reduced patient visibility can also change nursing workflow with implications for the physiological stability of infants, nurse handling of alarms and perceived alarm pressure.

In this study, we explore the differences in the number and duration of alarms for critical and alerting alarms as well as the interaction of clinicians with the patient monitor for two NICUs in the Netherlands. These NICUs have a comparable patient population and care setting with one NICU of an SFR design and the other of an OBA design. The aim of this comparative clinical audit was for benchmarking and sharing the collective operational experiences of two comparable NICUs to identify opportunities for improving alarm management and reducing noise exposure, both at the bedside and at the central posts, for infants and clinicians.

\section{MATERIALS AND METHODS \\ The NICU environment}

The Netherlands has a population of 17 million inhabitants with centralised neonatal intensive care organised in 10 level III centres across the country. The two participating NICUs, Máxima Medical Centre (MMC) Veldhoven and Isala Clinics Zwolle, have a typical annual admission rate of 380 and 330 patients, respectively. The 18-bed MMC NICU, constructed in 2012, is of an SFR design (nine single rooms, five double rooms and one triple room), while the 18-bed Isala NICU, constructed in 2014, has an OBA design (three rooms with six beds each). Figure 1 illustrates the architecture of these units and table 1 compares the characteristics of the units across several dimensions. Excluding the NICU design and the associated differences in alarm handling, the units are mostly similar regarding medical equipment, staffing patterns, the patient population and care practices. Notably, also, the nursing staff in both units has a comparable educational background and professional training since they are all drawn from a small and homogenous, Dutch-speaking population. Furthermore, in both units, the mix of clinicians is similar with neonatologists, fellows (paediatricians in training in neonatology), residents in paediatrics and physician assistants sharing the clinical workload.

\section{Alarm chain}

In both units, patient monitoring is carried out using Philips patient monitors (IntelliVue MX 800, Germany). Based on urgency, these patient monitors prioritise patient-related alarms into 'red' and 'yellow' alarms, corresponding to critical and alerting alarms, respectively. In both units, the primary alarm chain comprised the patient monitor, the interbed communication system and central monitors at the nursing stations, where it was possible to get an overview of alarms from all infants. In the SFR NICU, a secondary alarm chain was employed that used a distributed alarming system to send all red alarms to handheld devices carried by nurses, a detailed description of which has been published earlier. ${ }^{152}$ In the SFR NICU of the MMC, the ventilator (Fabian HFO, Acutronic, Switzerland) was also connected to the patient monitor to ensure that red ventilator alarms, including information on the nature of the alarm, were forwarded to the handheld devices carried by the nurses. Ventilator data for the OBA NICU was unavailable. Regarding alarm sounds, in both the SFR and the OBA NICUs, the red and yellow alarms generated sounds at the patient monitors and the central post.

Both units monitored the three-lead ECG, the respiration rate (using impedance pneumography), oxygen saturation $\left(\mathrm{SpO}_{2}\right.$; using disposable sensors), skin temperature and occasionally invasive arterial blood pressure of infants. $\mathrm{SpO}_{2}$ monitoring was carried out with an averaging setting of $10 \mathrm{~s}$ with alarms being generated after a user-adjustable delay if the $\mathrm{SpO}_{2}$ dropped and remained below a predefined threshold. The heart rate was calculated as the average of the 12 most recent beat-to-beat intervals or the four most recent beat-to-beat intervals if the heart rate was less than $80 \mathrm{bpm}$.

In both units, the threshold values for generating red alarms corresponding to desaturation, bradycardia and apnoea were $80 \%, 80 \mathrm{bpm}$ and $20 \mathrm{~s}$, respectively. Bradycardia and apnoea alarms were generated without any delays, while for desaturation alarms, the delay was $10 \mathrm{~s}$ and $20 \mathrm{~s}$ in the SFR and OBA NICUs, respectively. With regard to the yellow alarms concerning low and high heart rate, the median threshold values in both units were 100 and $200 \mathrm{bpm}$ with alarms generated without delay. In the SFR NICU, the median thresholds concerning low and high $\mathrm{SpO}_{2}$ were $85 \%$ and $95 \%$, with alarms being generated with a delay of $15 \mathrm{~s}$. In the OBA NICU, the corresponding thresholds were $88 \%$ and $95 \%$ with the delay set to $10 \mathrm{~s}$.

In addition to patient-related alarms, for both units, the patient monitors also stored logs for inoperative (INOP) alarms. These alarms logged situations when the monitor was unable to generate alarms (eg, ECG lead disconnection) or a clinician was interacting with the monitor (eg, silence alarms, pause alarms). Silencing stopped the alarm sounds of a single category of alarm (eg, bradycardia/desaturation) for up to $3 \mathrm{~min}$, after which, the alarm would start resounding if the underlying condition had not resolved. During the silence period, visual indicators of the alarm condition would continue to be displayed. The pause function stopped both the visual and auditory information on the status of alarms of all categories for up to $3 \mathrm{~min}$. 


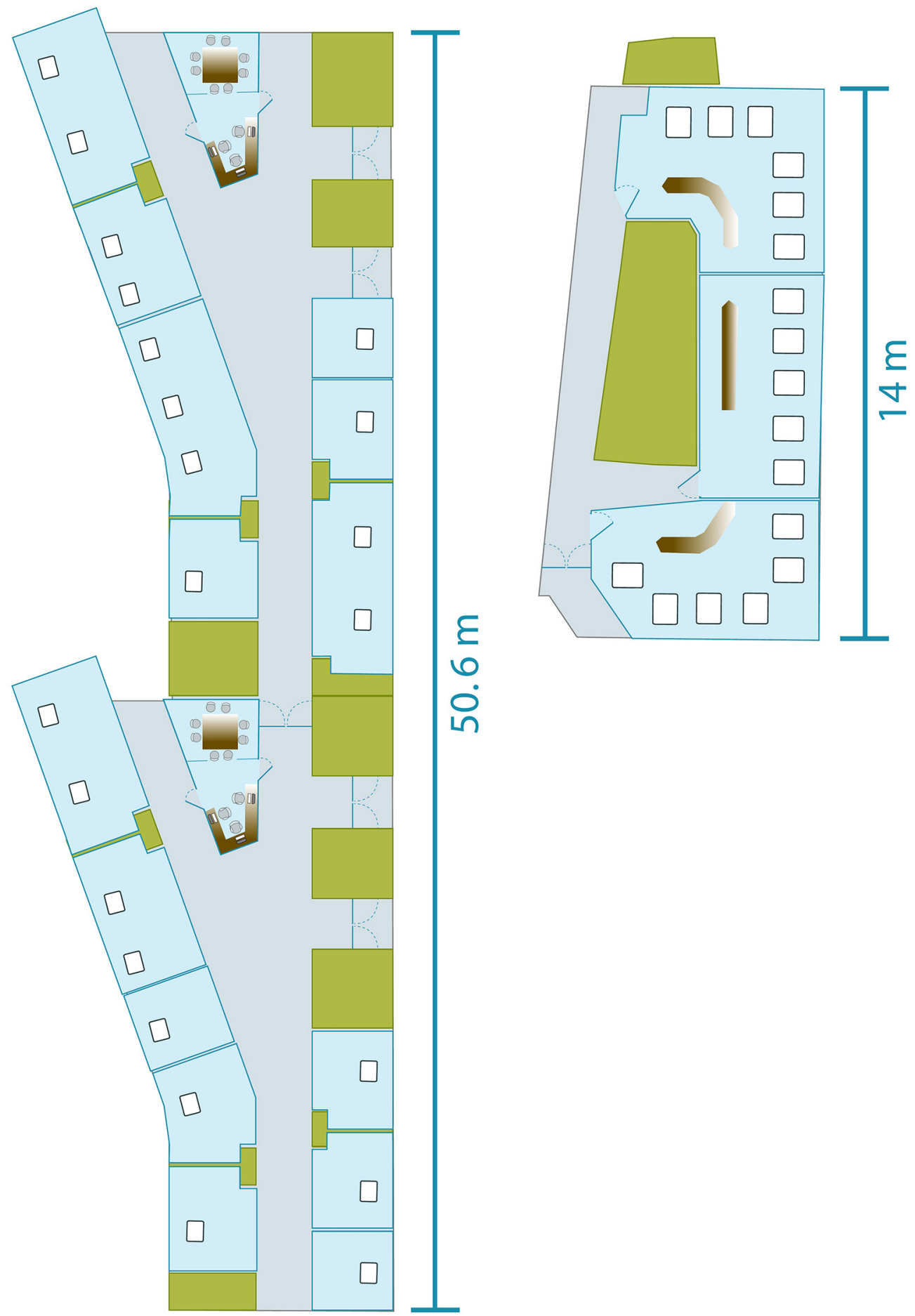

Figure 1 The architectural layout of the single-family room neonatal intensive care unit (NICU) (left) and the open bay area NICU (right). The white spaces indicate the incubator and the blue spaces indicate patient rooms. The green spaces indicate ancillary facilities like the pharmacy and closet space. Grey areas indicate corridors or dead space. Individually, the NICUs are drawn to scale.

\section{Alarm analysis}

All alarm data were extracted from the central posts, which maintain a running log of alarms up to 60 days prior. For all types of red, yellow and INOP alarms, the total number of alarms were counted and expressed as the number of alarms generated per patient per day at the unit level. For the ventilator alarms, the alarm pressure was calculated considering only the ventilated days of the study. The duration of each alarm was calculated based on the start and end time of alarms and expressed in median (IQR) duration. The threshold values that were breached when the alarm was generated were also extracted. For the most prevalent red, yellow and INOP alarms, the average number of alarms generated by 100 patients for each consecutive $10 \mathrm{~min}$ interval of time was plotted through the course of the day to visualise changes 
Table 1 Characteristics of neonatal intensive care units (NICUs) across several dimensions

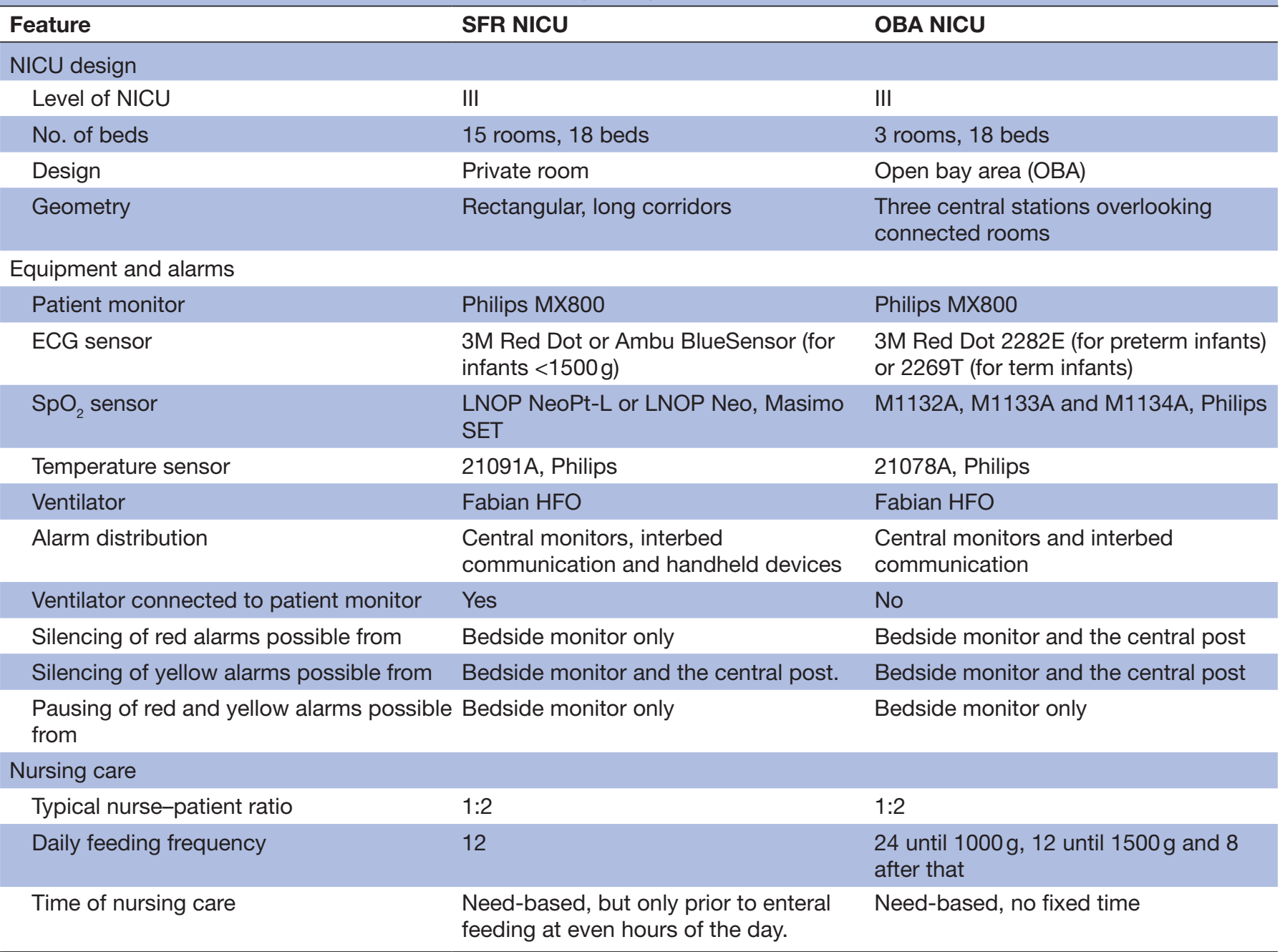

SFR, single-family room.

in alarm pressure and interaction of clinicians with the patient monitor. All data were analysed using Matlab R2015b (MathWorks, Massachusetts, USA).

\section{Patient demographics}

In totality, 2126 patient days (from 158 patients between 3 August 2016 and 30 December 2016) and 2035 patient days (from 170 patients between 26 June 2016 and 30 November 2016) were analysed from the NICUs at MMC and Isala, respectively. There were no exclusion criteria. This convenience sample of approximately 150 calendar days was chosen based on the expected frequency of occurrence of alarms from a previous audit. ${ }^{21}$ As is standard practice, this retrospective analysis of anonymised data, aimed at quality improvement, did not require ethical approval. The patient metadata and clinical characteristics of the infants enrolled in the study are shown in table 2. Statistical analysis of differences in patient metadata and clinical characteristics were carried out using the $\chi^{2}$ goodness of fit test (or Fisher's exact test where appropriate). A p value $\leq 0.05$ was considered statistically significant. Effect size as measured by proportion difference was carried out for statistically significant variables.

\section{Patient and public involvement}

All data were retrospectively acquired without involvement of any patients. There was no public involvement.

\section{RESULTS}

More than 150000 red alarms and nearly 1.2 million yellow alarms from patient monitors were analysed from 4161 patient days. The SFR NICU and the OBA NICU generated, on average, 42.4 and 23.4 red alarms per infant per day, respectively. For both units, the desaturation, bradycardia and apnoea alarms were the most common (table 3). While the number and duration of bradycardia alarms were similar for both units, the SFR NICU produced 2.5 times as many desaturation alarms per infant per day, but of shorter duration.

For yellow alarms, the SFR NICU and the OBA NICU generated, on average, 174.4 and 289.6 alarms per infant per day, respectively. The most prevalent alarms were 
Table 2 Patient metadata and clinical characteristics of the infants enrolled in the study

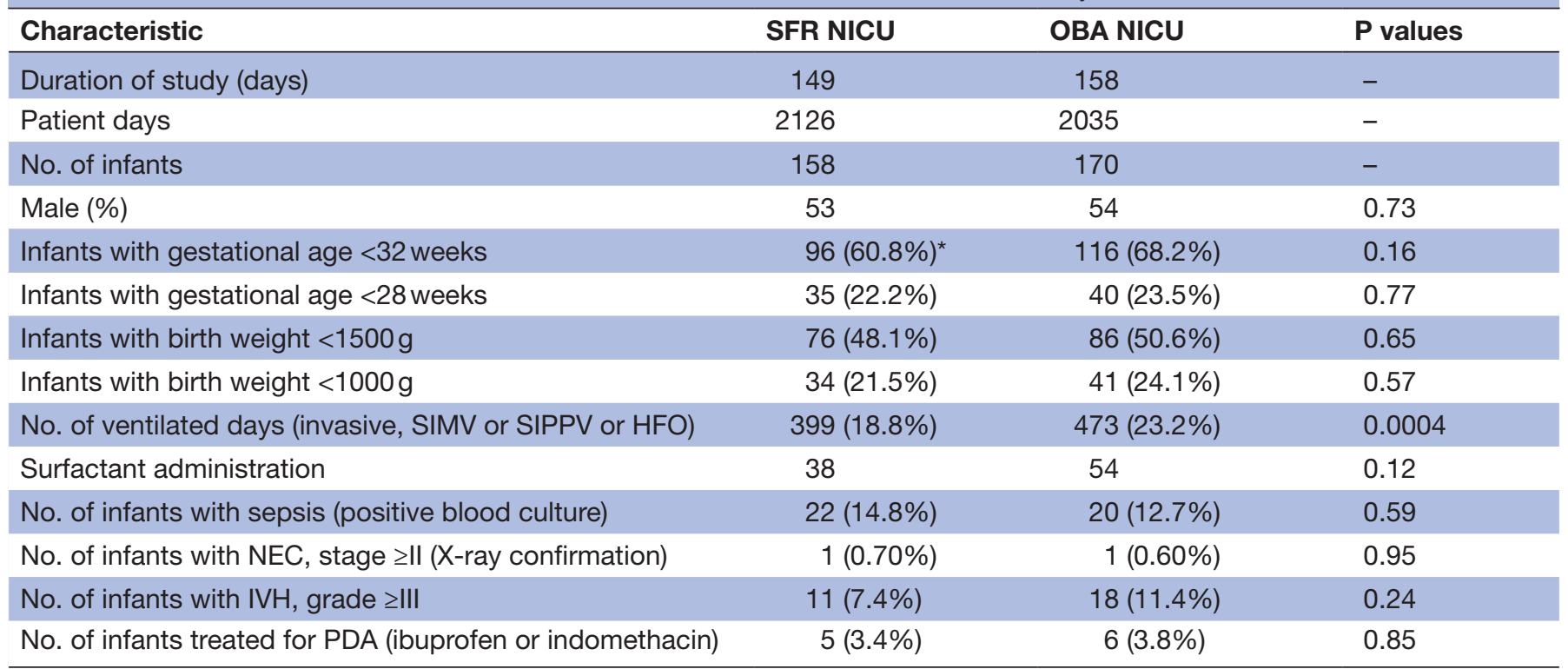

${ }^{*}$ All percentages are based on the number of infants or patient days for the corresponding NICU.

HFO, high-frequency oscillation; IVH, intraventricular hemorrhage; NEC, necrotizing enterocolitis; NICU, neonatal intensive care unit; OBA, open bay area;PDA, patent ductus arteriosus; SFR, single-family room; SIMV, synchronised intermittent mandatory ventilation; SIPPV, synchronised intermittent positive pressure ventilation.

the low and high $\mathrm{SpO}_{2}$ and heart rate alarms (table 3). The OBA NICU had $37.4 \%$ and $91.1 \%$ more low and high $\mathrm{SpO}_{2}$ alarms per infant per day, compared with the SFR NICU.

Overall, the OBA NICU generated $44 \%$ more patient monitor alarms per day. The distribution of red and yellow alarms through the course of the day, for all patient monitor alarms and their most prevalent subtypes, for both NICUs, is shown in figure 2. The number of red monitor alarms is higher in the SFR NICU while the number of yellow alarms is higher in the OBA NICU. The low $\mathrm{SpO}_{2}$ and desaturation alarms exhibit periodicity in their occurrence, as has been reported earlier. ${ }^{21} 22$

For the SFR NICU, logs of the ventilator alarms were available since ventilators were connected to patient monitors. Nearly 15000 red and 202000 yellow ventilator alarms were analysed. Appendix A shows that the ventilator alarms also exhibit a clear 2-hourly periodicity for both the red and yellow alarms. For the SFR NICU, while the patient monitor generates 42.4 and 174.4 red and yellow alarms per infant per day, the ventilator further adds 15 red and 206.5 yellow alarms, respectively. For red ventilator alarms, the most common alarms were the alarms corresponding to the disconnection of the ventilator circuit $(55.5 \%)$, problems with the endotracheal tube $(27.25 \%)$ and high peak inspiratory pressure $(15.4 \%)$. For the yellow alarms, the most common alarms corresponded to low inspiratory pressure $(72.4 \%)$, insufficient volume delivery $(7.3 \%)$, low minute volume $(4.6 \%)$ and low positive end-expiratory pressure $(4.2 \%)$.

With regard to the interaction of clinicians with the patient monitor, nurses pause alarms (all categories of alarms get paused) more often in the SFR NICU while nurses in the OBA NICU silence alarms much more often. For the alarms that were silenced, the alarm condition persisted beyond $3 \mathrm{~min}$ for nearly one-third of the alarms in the OBA NICU as opposed to $11 \%$ in the SFR NICU, leading to resounding of alarms (table 3).

Notably, patient characteristics between the two units were comparable ( $p$ value $>0.05$ ) with the exception of ventilated days ( $p$ value $<0.01$ ). However the effect size, as measured by proportion difference, for ventilated days is small with the OBA NICU having a $4.5 \%$ higher risk of ventilation.

\section{DISCUSSION}

The number of audible patient monitor alarms (red+yellow+technical INOP) is high for NICUs of both the SFR and the OBA design, as has been reported earlier. ${ }^{15} 1621-25$ However, the number of alarms and the associated noise pollution vary considerably with the OBA NICU generating $44 \%$ more alarms per patient per day. Multiple studies in different NICUs have shown a periodic increase in alarms through the course of the day, and this periodicity can be observed for both NICUs included in this study. ${ }^{152} 22$ This periodic increase in alarms has been found to be associated with both nursing care events as well as the delivery of enteral feeds. ${ }^{26}$ The SFR NICU of this study had a 2-hourly frequency of enteral feeding, and this is reflected in a 2-hourly increase in alarms. The peaks in alarm pressure for the OBA NICU are less clear since the frequency of enteral feeding was dependent on the weight of infants with a frequency of once every 1-3 hours (see table 1 ). The periodic increase in the interaction of clinicians with the patient monitor 
Table 3 Characteristics of the red (desaturation, bradycardia and apnoea), yellow (low and high $\mathrm{SpO}_{2}$ and heart rate) and INOP alarms for the SFR and OBA NICUs of MMC and Isala

\begin{tabular}{|c|c|c|c|c|c|}
\hline Alarm type & $\begin{array}{l}\text { NICU design } \\
\text { (delay*) }\end{array}$ & $\begin{array}{l}\text { Mean no. daily of } \\
\text { alarms/infant }\end{array}$ & $\%$ of total alarms & $\begin{array}{l}\text { Median (IQR) } \\
\text { duration of } \\
\text { alarm (s) }\end{array}$ & $\begin{array}{l}\text { Mean daily duration } \\
\text { of alarm/infant } \\
\text { (min) }\end{array}$ \\
\hline \multirow[t]{2}{*}{ Desaturation } & SFR (10s) & 31.76 & $75.14 \dagger$ & $10(4-23)$ & 10.65 \\
\hline & OBA (20s) & 13.22 & 56.47 & $17(7-41)$ & 7.59 \\
\hline \multirow[t]{2}{*}{ Bradycardia } & SFR (0s) & 7.27 & 17.20 & $5(3-12)$ & 1.05 \\
\hline & OBA (0s) & 7.14 & 30.49 & $5(3-12)$ & 1.07 \\
\hline \multirow[t]{2}{*}{ Apnoea } & SFR (0s) & 0.92 & 2.18 & $9(5-19)$ & 0.24 \\
\hline & OBA (0s) & 1.19 & 5.09 & $9(4-16)$ & 0.29 \\
\hline \multirow[t]{2}{*}{$\mathrm{SpO}_{2}$ low } & SFR (15s) & 88.98 & 51.03 & $14(6-30)$ & 38.70 \\
\hline & OBA (10s) & 122.25 & 42.22 & $14(6-31)$ & 55.33 \\
\hline \multirow[t]{2}{*}{$\mathrm{SpO}_{2}$ high } & SFR (15s) & 53.08 & 30.43 & $26(10-64)$ & 47.70 \\
\hline & OBA (10s) & 101.46 & 35.04 & 12(5-32) & 55.72 \\
\hline \multirow[t]{2}{*}{ Heart rate low } & SFR (0s) & 15.04 & 8.62 & $5(3-8)$ & 1.59 \\
\hline & $\mathrm{OBA}(0 \mathrm{~s})$ & 13.27 & 4.58 & $5(3-8)$ & 1.41 \\
\hline \multirow[t]{2}{*}{ Heart rate high } & SFR $(0 s)$ & 11.82 & 6.77 & $8(4-20)$ & 3.42 \\
\hline & $\mathrm{OBA}(0 \mathrm{~s})$ & 17.13 & 5.91 & $8(4-20)$ & 5.04 \\
\hline \multirow[t]{2}{*}{ Silence } & SFR & 17.49 & - & - & - \\
\hline & OBA & 59.42 & - & - & - \\
\hline \multirow[t]{2}{*}{ Pause } & SFR & 9.3 & - & - & - \\
\hline & OBA & 3.35 & - & - & - \\
\hline \multirow[t]{2}{*}{ Technical alarms } & SFR (0s) & 4 & - & - & - \\
\hline & OBA (0s) & 3.88 & - & - & - \\
\hline \multirow{2}{*}{$\begin{array}{l}\text { Resounding of } \\
\text { alarms }\end{array}$} & SFR & 1.67 & - & - & - \\
\hline & OBA & 22 & - & - & - \\
\hline
\end{tabular}

*Delay corresponds to the delay before generating the alarm once the threshold is breached.

†Percentages correspond to contribution of alarms from the same category (red/yellow).

INOP, inoperative; MMC, Máxima Medical Centre; NICU, neonatal intensive care unit; OBA, open bay area; SFR, single-family room.

(figure 2) indicates an attempt to suppress alarm-related noise during these periods.

The higher incidence of red alarms in the SFR NICU is primarily due to more desaturation alarms, likely due to a shorter delay ( $10 \mathrm{~s}$ as opposed to $20 \mathrm{~s}$ in the OBA NICU) in generating the desaturation alarm once the threshold value ( $80 \%$ in both units) is breached. ${ }^{25}$ Irrespective of the averaging setting employed, longer delays allow the oxygen saturation levels to recover, resulting in fewer alarms of a longer duration, which is unsurprising since they arise due to desaturation events that did not resolve spontaneously within the set delay period. ${ }^{25}$

In a previous study carried out in the SFR NICU of MMC, we identified that the median nurse response times to red desaturation alarms was quite long at $56 \mathrm{~s} .{ }^{19}$ Since extended desaturation events are associated with adverse outcomes, there is a natural tendency for SFR NICUs to err on the side of caution and opt for shorter delays. ${ }^{27}$ However, for the OBA NICUs with direct visual oversight and potentially shorter distances and nurse response times, slightly longer delays in generating the alarm, on average, help in reducing the mean daily duration for which the alarms sound and reduce noise in the typically noisier OBA environment. ${ }^{28-30}$ The choice of delay gets further challenged since a study has shown that in infants born small for gestational age, a high incidence of even short hypoxaemic events $(20 \mathrm{~s})$ within 3 days of birth is associated with higher mortality at 90 days of life. ${ }^{31}$ Therefore, we should contemplate dynamically adjusting not just alarm thresholds but also alarm delays, based on the vulnerability profile of infants, with shorter delays in place for the most vulnerable infants. In summary, there exists a delicate tradeoff between the choice of alarm delays and the risk of alarm fatigue. ${ }^{32}$ Quantifying alarm pressure as described in this study is an important step in assessing the risk of alarm fatigue. It also serves as a baseline measure that can be used to contrast changes in alarm settings such as delays that may affect alarm pressure.

The incidence of yellow alarms is higher for the OBA NICU, primarily because of more low and high $\mathrm{SpO}_{2}$ alarms. The higher incidence of low $\mathrm{SpO}_{2}$ alarms is largely due to a narrower alarm limit $(88 \%-95 \%$; median values of alarm thresholds), evidence of which can also be found elsewhere. ${ }^{22}$ Furthermore, in comparison with the 

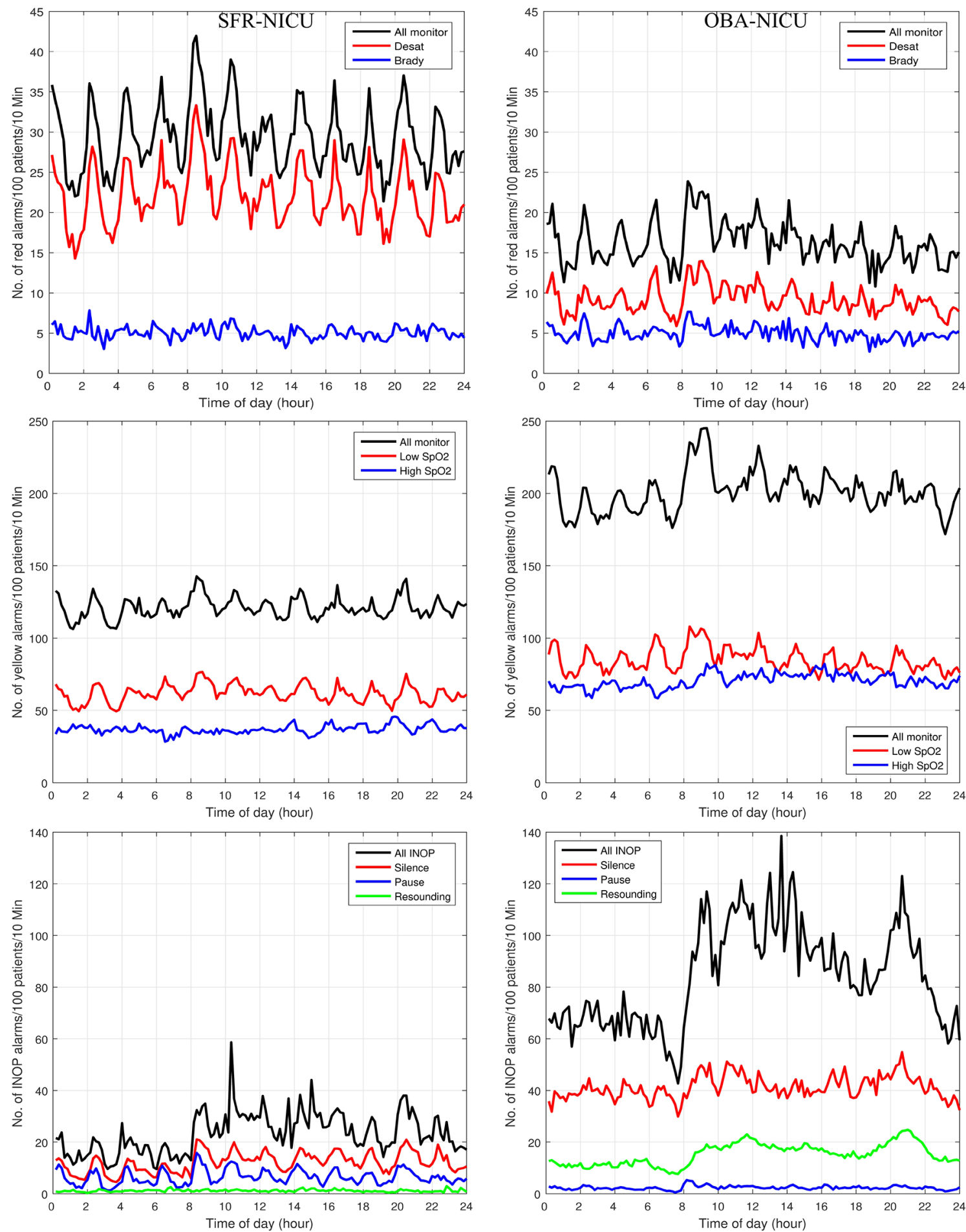

Figure 2 The average number of logs corresponding to red (top), yellow (middle) and inoperative (INOP) (bottom) alarms measured during the study period plotted through the 24 hours of the day in the single-family room neonatal intensive care unit (SFR NICU) (left column) and the open bay area (OBA) NICU (right column). The alarm rate is shown for 100 patients per 10 min. Note that the resolution of the $y$-axis varies for each row of subplots.

SFR NICU, the delay for yellow alarms is shorter $(10 \mathrm{~s}$ as opposed to $15 \mathrm{~s}$ in the SFR NICU), which leads to more alarms. The considerably larger number of high $\mathrm{SpO}_{2}$ alarms is difficult to explain but important to consider since hyperoxaemia is associated with an increased risk of retinopathy of prematurity. It should be noted that alarms for high $\mathrm{SpO}_{2}$ are off when infants are breathing room air, so all alarms corresponding to high $\mathrm{SpO}_{2}$ originate solely from infants on intermittent supplemental oxygen. While the greater number of high $\mathrm{SpO}_{2}$ alarms in the OBA NICU might partly be due to the shorter delay in generating the alarm, it might also be due to rebound hyperoxaemia as a result of nurses increasing supplemental oxygen to combat a large number of low 
$\mathrm{SpO}_{2}$ alarms. ${ }^{33}$ This rationale is further supported by the finding that for $37.5 \%$ of high $\mathrm{SpO}_{2}$ alarms, thresholds were set to higher than $95 \%$, while in the SFR NICU, only $16 \%$ of high $\mathrm{SpO}_{2}$ alarms had a threshold higher than 95\% (data not shown but calculated from the alarm logs of these units).

Regarding ventilator alarm management, as has been pointed out by the ECRI Institute and research groups, multiple challenges exist. ${ }^{34-36}$ In particular, the ECRI Institute highlights that collecting and analysing ventilator data can be challenging, and limited research exists on ventilator alarms. ${ }^{19} 2437$ To the best of our knowledge, this study is the largest audit of ventilator alarms, and we show that the daily alarm pressure (average) because of ventilators, in fact, exceeds that due to patient monitors alone. It should be noted that although on average ventilator alarm pressure is high, it is also dependent on the mode of ventilation. The periodic increases in ventilator alarms (online supplementary file), similar to the pattern observed in patient monitor alarms, might be in response to nursing care (eg, endotracheal suctioning) and enteral feeding. ${ }^{26}$ Opportunities to reduce ventilator-related alarms have been suggested elsewhere. ${ }^{37}$

In the OBA NICU, the exposure of infants to alarm sounds is likely higher since both the number of daily alarms (red+yellow+technical INOP) is higher and the mean daily duration for which alarms sound is longer (table 3). Furthermore, in an OBA environment, there is greater exposure to alarm sounds originating from other infants. Noise due to alarms, as experienced by the nurses, is also likely higher in the OBA NICU since nurses are exposed to both red and yellow alarms originating from all infants. In the SFR NICU, nurses receive red alarms on handheld devices and therefore spend less time at the central post and likely experience fewer alarm sounds. In the OBA NICU, nurses silence alarms more often than in the SFR NICU, probably because they spend more time at the central post as opposed to nurses in the SFR NICU who have handheld devices and are safe in the knowledge that all red alarms will be transmitted to them. In both units, pausing alarms was possible only at the patient monitors (bedside). Nurses in the SFR NICU paused alarms more often than nurses in the OBA NICU. This behaviour might be because nurses in the SFR setting do not have visual oversight of the infants in their charge and might tend to respond to alarms by visiting the bedside more frequently and thereby creating more opportunities to pause alarms.

In this study, we compared alarm pressure between two NICUs, one of an SFR design and the other of an OBA design. In other aspects, both units are comparable since they use similar monitoring equipment and have similar patient populations and alarm handling protocols - with a nurse response expected to red alarms while yellow alarms serve as alerts. However, the non-randomised nature of the study is an unavoidable limitation despite the fact that the units are comparable with regard to the case mix as measured by patient data including gestational age, birth weight and mortality (acquired from the Dutch perinatal registry, data not shown). Furthermore, differences in nurse characteristics of the two units can also affect alarm pressure, but these differences are expected to be minimal since all nurses are drawn from a small and homogenous Dutch-speaking population with a comparable educational and professional background. Nevertheless, certain local factors, such as the immediate availability of other clinical personnel such as residents, can affect the delivery of care and thereby the alarm pressure. The results of the audit of patient monitoring alarms of the two NICUs show that considerable differences in alarm pressure exist, and these are at least partly attributable to the delays set in generating alarms. The choice of alarm thresholds and delays and thereby the exposure of infants and nurses to alarm sounds are in turn related to the architectural layout of the NICUs. In the two NICU designs studied, the burden of alarms and exposure to alarm sounds experienced by infants and nurses is higher in the OBA NICU. Additionally, there might also be a relationship between excessive exposure to alarm sounds and the changing of upper alarm limits for $\mathrm{SpO}_{2}$ alarms, potentially leading to $\mathrm{SpO} 2$ levels not staying within guideline recommendations. ${ }^{38}$ In particular, this has clinical implications associated with the distribution of oxygen saturation in preterm infants, especially if the target range for $\mathrm{SpO}_{2}$ is narrow. ${ }^{39}$ While alarm fatigue and the consequent increase in the risk of missed alarms is detrimental to clinical outcomes in all settings, within the NICU context, the associated noise is particularly disruptive to the short-term stability of the cardiac and respiratory systems as well as the sleep cycles of infants. Alarm-related noise is also stressful to staff and negatively affects the work environment. ${ }^{40-42}$

Recently, the OBA NICU of this study has introduced a portable and non-audible alarm system to reduce noise in the unit with alarms sounding only at the central post. Implementing such a system reduces noise pollution in the NICU, originally a key advantage of the SFR design. Because of architectural layout and typically shorter distances from the central post to the bedside, OBA NICUs are better positioned to implement longer delays for generating alarms. Based on the results of this study, we can identify that in the OBA NICU, implementing longer delays, for example, 20s for yellow $\mathrm{SpO}_{2}$ alarms, will reduce the corresponding alarms by more than $50 \%$, leading to lower noise exposure for nurses at the central post. Furthermore, in the OBA NICU of this study, by introducing even an $8 \mathrm{~s}$ delay for yellow alarms corresponding to low and high heart rate, $75 \%$ and $50 \%$ of these alarms can be eliminated (table 3 ).

About the SFR NICU in the study, sounding yellow alarms at the bedside where no clinician is present for the vast majority of the day does not serve to draw the attention of the caregiver to the clinical status of the infant. These alarms, however, contribute to more than $80 \%$ of the noxious noise experienced by the infant. In comparison with the new alarm system of the OBA NICU, the 
potential benefits of the SFR design, at least with regard to lower exposure to noxious sounds, may not be fully realised unless close attention is paid to the choices for communicating alarms to the caregivers.

To conclude, for the design of new NICUs and the remodelling of older units, in addition to the various aspects such as the nurse-patient ratios that are typically considered, attention should also be paid to how the architectural layout and the consequent choices for alarm settings and alarm distribution affect alarm pressure and by association alarm fatigue. ${ }^{43-45}$ If non-audible alarm systems can be implemented, the opportunity to implement longer delays in the OBA NICUs, at least for yellow alarms, can lead to reduced alarm pressure in comparison with SFR NICUs.

\section{Author affiliations}

${ }^{1}$ Department of Industrial Design, Eindhoven University of Technology, Eindhoven, The Netherlands

${ }^{2}$ Department of Clinical Physics, Maxima Medisch Centrum locatie Veldhoven, Veldhoven, Noord-Brabant, The Netherlands

${ }^{3}$ Department of Neonatology, Isala, Zwolle, The Netherlands

${ }^{4}$ Department of Neonatology, Maxima Medisch Centrum locatie Veldhoven, Veldhoven, The Netherlands

${ }^{5}$ Department of Fertility, Pregnancy, and Parenting Solutions, Philips Research Eindhoven, Eindhoven, The Netherlands

${ }^{6}$ Department of Electrical Engineering, Technische Universiteit Eindhoven, Eindhoven, The Netherlands

${ }^{7}$ Department of Applied Physics, Technische Universiteit Eindhoven, Eindhoven, The Netherlands

Acknowledgements This research was performed within the framework of IMPULS perinatology.

Contributors RJ, HS, PA and CP designed the study. HS, HM and PA provided clinical input while RJ carried out the technical analysis and was assisted by XL and CP. RJ wrote the first draft of the paper and all authors reviewed and critically revised the manuscript. All authors read and approved the final version of the manuscript.

Funding This research received no specific grant from any funding agency in the public, commercial or not-for-profit sectors.

Competing interests None declared.

Patient consent Not required.

Provenance and peer review Not commissioned; externally peer reviewed.

Data sharing statement All relevant data are available within the paper. The original patient data cannot be made public since it constitutes sensitive and confidential information that is protected by European privacy laws. The authors may be contacted for additional information.

Open access This is an open access article distributed in accordance with the Creative Commons Attribution Non Commercial (CC BY-NC 4.0) license, which permits others to distribute, remix, adapt, build upon this work non-commercially, and license their derivative works on different terms, provided the original work is properly cited, appropriate credit is given, any changes made indicated, and the use is non-commercial. See:@http://creativecommons.org/licenses/by-nc/4.0/.

\section{REFERENCES}

1. Stevens DC, Munson DP, Khan MA. The single-family room neonatal intensive care environment. Neoreviews 2016;17:e687-96.

2. Smith J, Bajo K, Hager J. Planning a developmentally appropriate neonatal intensive care unit. Clin Perinatol 2004;31:313-22.

3. Lester BM, Hawes K, Abar B, et al. Single-family room care and neurobehavioral and medical outcomes in preterm infants. Pediatrics 2014;134:754-60.
4. Vohr B, McGowan E, McKinley L, et al. Differential effects of the single-family room neonatal intensive care unit on 18- to 24-Month Bayley scores of preterm infants. J Pediatr 2017;185:42-8.

5. Stevens D, Thompson P, Helseth $\mathrm{C}$, et al. Mounting evidence favoring single-family room neonatal intensive care. J Neonatal Perinatal Med 2015;8:177-8.

6. Kudchadkar SR, Beers MC, Ascenzi JA, et al. Nurses' perceptions of pediatric intensive care unit environment and work experience after transition to single-patient rooms. Am J Crit Care 2016;25:e98-107.

7. Stevens DC, Helseth CC, Thompson PA, et al. A comprehensive comparison of open-bay and single-family-room neonatal intensive care units at Sanford Children's Hospital. Heal Environ Res Des J 2012;5:23-39.

8. Stevens DC, Thompson PA, Helseth CC, et al. A comparison of the direct cost of care in an open-bay and single-family room NICU. $J$ Perinatol 2014;34:830-5.

9. Watson J, DeLand M, Gibbins S, et al. Improvements in staff quality of work life and family satisfaction following the move to single-family room NICU design. Adv Neonatal Care 2014:14:129-36.

10. Swanson JR, Peters C, Lee BH. NICU redesign from open ward to private room: a longitudinal study of parent and staff perceptions. $J$ Perinatol 2013;33:466-9.

11. Domanico R, Davis DK, Coleman F, et al. Documenting the NICU design dilemma: comparative patient progress in open-ward and single family room units. $J$ Perinatol 2011;31:281-8.

12. Harris DD, Shepley MM, White RD, et al. The impact of single family room design on patients and caregivers: executive summary. Journal of Perinatology 2006;26:S38-48.

13. White RD. Individual rooms in the NICU - an evolving concept. $J$ Perinatol 2003;23(Suppl 1):S22-4.

14. Dunn MS, MacMillan-York E, Robson K. Single family rooms for the NICU: pros, cons and the way forward. Newborn and Infant Nursing Reviews 2016;16:218-21.

15. van Pul C, V D Mortel HP, V D Bogaart JJ, et al. Safe patient monitoring is challenging but still feasible in a neonatal intensive care unit with single family rooms. Acta Paediatr 2015;104:e247-54.

16. Walsh MC, Powers E, Fanaroff J. The potential for harm from alarm fatigue in single-room NICUs. Acta Paediatr 2015;104:436-7.

17. Johnson KR, Hagadorn JI, Sink DW. Alarm safety and alarm fatigue. Clin Perinatol 2017:44:713-28.

18. Sendelbach S, Fatigue ANurs Clin North Am 2012;47:375-82.

19. Joshi R, Mortel Hvande, Feijs L, et al. The heuristics of nurse responsiveness to critical patient monitor and ventilator alarms in a private room neonatal intensive care unit. PLOS One 2017;12:e0184567.

20. Wachman EM, Lahav A. The effects of noise on preterm infants in the NICU. Arch Dis Child Fetal Neonatal Ed 2011;96:F305-F309.

21. Joshi $R$, van Pul C, Atallah $L$, et al. Pattern discovery in critical alarms originating from neonates under intensive care. Physiol Meas 2016;37:564-79

22. Ketko AK, Martin CM, Nemshak MA, et al. Balancing the tension between hyperoxia prevention and alarm fatigue in the NICU. Pediatrics 2015;136:e496-504.

23. Vergales BD, Paget-Brown AO, Lee $\mathrm{H}$, et al. Accurate automated apnea analysis in preterm infants. Am J Perinatol 2014;31:157-62.

24. Pul C, Joshi R, Dijkman W. et alAlarm management in a singlepatient room intensive care units. In: Chen W, Augusto JC, Seoane F, Lehocki F, Wolf K-H, Arends J, Constantin Ungureanu RW, . eds. Recent advances in ambient assisted living - bridging assistive technologies, e-health and personalized health care: IOS Press, 2015:119-32.

25. McClure C, Jang SY, Fairchild K. Alarms, oxygen saturations, and SpO2 averaging time in the NICU. J Neonatal Perinatal Med 2016:9:357-62.

26. Joshi R, van Pul C, Sanders A, et al. A strategy to reduce critical cardiorespiratory alarms due to intermittent enteral feeding of preterm neonates in intensive care. Interact J Med Res 2017;6:e20.

27. Poets CF, Roberts RS, Schmidt B, et al. Association between intermittent hypoxemia or bradycardia and late death or disability in extremely preterm infants. JAMA 2015;314:595-603.

28. Walsh WF, McCullough KL, White RD. Room for improvement: nurses' perceptions of providing care in a single room newborn intensive care setting. Adv Neonatal Care 2006;6:261-70.

29. Liu WF. Comparing sound measurements in the single-family room with open-unit design neonatal intensive care unit: the impact of equipment noise. J Perinatol 2012;32:368-73.

30. Helseth CC, Ak M, Munson DP, et al. The effect of neonatal intensive care unit design on the distance walked by nurses keywords : introduction pedometer measurements. J Nurs Heal Stud 2016:1:12-15. 
31. Di Fiore JM, Martin RJ, Li H, et al. Patterns of oxygenation, mortality, and growth status in the surfactant positive pressure and oxygen trial cohort. J Pediatr 2017;186:49-56.

32. Görges M, Markewitz BA, Westenskow DR. Improving alarm performance in the medical intensive care unit using delays and clinical context. Anesth Analg 2009;108:1546-52.

33. van Zanten HA, Tan RN, Thio M, et al. The risk for hyperoxaemia after apnoea, bradycardia and hypoxaemia in preterm infants. Arch Dis Child Fetal Neonatal Ed 2014:99:F269-73.

34. ECRI. Top 10 Health Technology Hazards for Top 10 Health Technology Hazards for. 2017.

35. Stokes JE, Manzoor SH, Cvach MM, et al. Ventilator alarms: challenges and opportunities for improvement. Biomed Instrum Technol 2017;51:390-7.

36. Poets CF. Reducing alarms in the NICU. Arch Dis Child Fetal Neonatal Ed 2017:fetalneonatal-2017-314259.

37. Belteki G, Morley CJ. Frequency, duration and cause of ventilator alarms on a neonatal intensive care unit. Arch Dis Child Fetal Neonatal Ed 2017:fetalneonatal-2017-313493.
38. Sola A, Golombek SG, Montes Bueno MT, et al. Safe oxygen saturation targeting and monitoring in preterm infants: can we avoid hypoxia and hyperoxia? Acta Paediatr 2014;103:1009-18.

39. van Zanten HA, Pauws SC, Stenson BJ, et al. Effect of a smaller target range on the compliance in targeting and distribution of oxygen saturation in preterm infants. Arch Dis Child Fetal Neonatal Ed 2017:fetalneonatal-2016-312496.

40. Cvach M. Monitor alarm fatigue: an integrative review. Biomed Instrum Technol 2012;46:268-77.

41. Altimier L, Phillips RM. The neonatal integrative developmental care model: seven neuroprotective core measures for familycentered developmental care. Newborn and Infant Nursing Reviews 2013;13:9-22.

42. Wachman EM, Lahav A. The effects of noise on preterm infants in the NICU. Arch Dis Child Fetal Neonatal Ed 2011;96:F305-9.

43. Halpern NA. Innovative designs for the smart ICU: part 1: from initial thoughts to occupancy. Chest 2014;145:399-403.

44. Halpern NA. Innovative Designs for the Smart ICU: Part 2: The ICU. Chest 2014;145:903-12.

45. Halpern NA. Innovative designs for the smart ICU: Part 3: advanced ICU informatics. Chest 2014;145:903-12. 